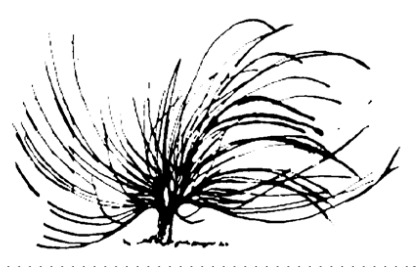

\title{
$O$ processo de formação docente pela escrita do relatório de estágio
}

\author{
Sulemi Fabiano-Campos ${ }^{1}$ \\ Universidade Federal do Rio Grande do Norte \\ Brasil \\ sulemifabiano@yahoo.com.br
}

Katia Cilene Ferreira França ${ }^{2}$

Universidade Federal do Maranhão

Brasil

katiacfranca@yahoo.com.br

\begin{abstract}
Resumo
Neste trabalho, nosso objetivo consiste em realizar uma análise sobre o modo como estagiários do curso de Letras mobilizam o discurso outro para fundamentar teoricamente a escrita do relatório de estágio. A discussão que propomos parte da concepção de que o relatório é um enunciado produzido como uma atividade responsiva sobre o processo formativo de futuros professores de língua materna, sobre os modos como os estagiários compreendem pontos de vista teóricos e como os relacionam com a realidade observada na sala de aula. Para a análise proposta, nos apoiamos na concepção de Bakhtin/Volóchinov (2006) sobre linguagem como atividade dialógica e sobre o discurso outro na produção
\end{abstract}

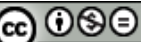

http://dx.doi.org/10.15359/rep.esp-20-1.4

1 Doutora em Linguística. Professora do Departamento de Letras e do Programa de Pós-Graduação em Estudos da Linguagem (PPgEL), líder do Grupo de Pesquisa em Estudos do Texto e do Discurso (GETED) da Universidade Federal do Rio Grande do Norte (UFRN) e pesquisadora do Grupo de Estudos e Pesquisa Produção Escrita e Psicanálise - GEPPEP. Pesquisadora do projeto.

2 Doutora em Estudos da Linguagem. Professora do curso de Linguagens e Códigos - Língua Portuguesa, da Universidade Federal do Maranhão (UFMA). Líder do Grupo de Estudos Escrita e Produção de Saberes (GETED), membro do Grupo de Pesquisa em Estudos do Texto e do Discurso (GETED) da Universidade Federal do Rio Grande do Norte (UFRN). 
de enunciados. Nosso objeto de análise são relatórios, produzidos em diferentes etapas do estágio curricular, diferentes escritas e espaços-tempos que nos ajudam a pensar sobre os deslocamentos de alunos ao mobilizar a palavra alheia para a construção e comentário real a partir dos sentidos que carrega.

Palavras chave: relatório de estágio; professor em formação; discurso outro.

\begin{abstract}
In this paper, our objective is to carry out an analysis on how undergraduate language interns mobilize the other's speech to theoretically base the writing of the internship report. The discussion that we propose comes from the conception that the report is a statement produced as a responsive activity in the training process of future mother tongue teachers in the ways in which the interns understand theoretical points of view and how they relate to the reality observed in the classroom. For the proposed analysis, we support the conception of Bakhtin/ Volóchinov (2006) about language as a dialogical activity and about the other's speech in the production of statements. Our analysis objects are reports produced in different stages of the curricular internship, different writings, and space-times that help us to think about the displacements of students by mobilizing the foreign word for the construction and real comment on the meanings it carries.
\end{abstract}

Keywords: internship report, teacher in training, other's speech

\title{
INTRODUÇÃO
}

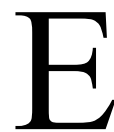

ste trabalho compreende um movimento reflexivo sobre a produção escrita nas universidades brasileiras, especificamente sobre os relatórios de estágio supervisionado de graduandos do curso de Letras, cuja finalidade institucional é ser o registro da relação do estagiário, enquanto professor em formação com a sala de aula, considerando que a escola não se resume a um espaço físico, mas é um 
lugar feito por pessoas, um lugar social, com a finalidade de promover o ensino e a aprendizagem.

Voltar atenção para o relatório não é apenas enxergar um documento burocrático, organizado à luz de um manual, mas observar a partir da escrita: 1) as imagens que o professor em formação tem da escola, da sala de aula, dos alunos, da aula de língua materna, da docência; 2) como esse professor relaciona a teoria aprendida como a prática de ensino; 3 ) como faz o uso dos discursos, que representam o saber científico, para fundamentar suas reflexões, para se posicionar como profissional com ensino superior. $\mathrm{O}$ diálogo com as pesquisas sobre a língua e o ensino é um elemento definidor da formação do professor, um diferencial entre o profissional graduado e aquele que não tem habilitação, mas ainda assim conduz o ensino em muitas salas de aula, porque no dizer de Geraldi (2010) sabe o saber produzido por outros e o transmite.

São amplas as perspectivas para tratar o relatório de estágio. A complexidade dessa escrita não pode ser desvendada de imediato. Nesse sentido, estabelecemos para este artigo uma delimitação. Nossa dúvida volta-se para os modos como o futuro professor dialoga como as vozes representantes do discurso acadêmico ${ }^{3}$. Que vozes são convocadas? Como essas vozes são utilizadas na fundamentação teórica do relatório ${ }^{4}$ ? O que esses usos do discurso acadêmico dizem sobre a formação de futuros professores? Esses questionamentos levam em conta os estudos bakhtinianos sobre o dialogismo na linguagem, ou seja, vamos abordar a relação do estagiário e os discursos outros sob o ponto de vista da língua como interação, da palavra como uma arena de lutas, do sujeito como um ser social, a compreensão como resposta a um signo por meio de signos (Bakhtin/ Volóchinov, 2006).

Nosso objetivo está em analisar, no relatório de estágio de alunos de letras, o diálogo entre o futuro professor e os discursos acadêmicos convocados como fundamento de suas reflexões sobre o ensino de língua. Para realizar a análise a que nos propomos, delimitamos um

3 Consideramos discurso acadêmico os saberes produzidos e legitimados na universidade, enquanto estudos desenvolvidos e que são apresentados aos graduandos como aporte teórico para compreender os fenômenos da língua em uso e pensar as práticas de ensino dessa língua.

4 Os relatórios de estágio são organizados segundo as orientações das normas de estágio e as indicações do professor responsável por esse componente curricular na graduação. Nos relatórios coletados, verificamos uma parte inicial destinada à apresentação de um aporte teórico antes da descrição da aula. 
conjunto de relatórios elaborados por alunos do Letras de uma universidade brasileira durante as diferentes etapas do estágio. Os resultados que encontramos apontam para desarticulação entre a voz representante do saber acadêmico e a voz do estagiário, um desencontro que, por sua recorrência, mostra imaturidade do estagiário enquanto leitor, logo como problematizador.

A fim de organizar a apresentação da pesquisa, dividimos este artigo em três partes: a primeira, referente aos estudos bakhtinianos, aborda a relação entre o eu e o outro no relatório, a partir do dialogismo; a segunda, que trata da apresentação e descrição do corpus; e a terceira, voltada especificamente para a análise de dados.

Antes de iniciar a primeira parte, destacamos que esta não é uma investigação finalizada nem isolada. Ela está em curso e compõe o projeto internacional "A escrita sobre as práticas de ensino em licenciaturas do Brasil, da Costa Rica e de Honduras: registro, análise e produção de conhecimento" (CNPq 458449/2014-8), formado por pesquisadores que veem relatórios de estágio, diários de campo, planos de aula como um terreno fértil a ser investigado. Trata-se, portanto, de um investimento cujos resultados têm a intenção de contribuir para o desenvolvimento dos cursos de formação de professor.

\section{EU E O OUTRO: UMA RELAÇÃO DIALÓGICA CONSTITUTI- VA DA LINGUAGEM}

A orientação dialógica é naturalmente um fenômeno próprio a todo discurso. [...] Em todos os seus caminhos até o objeto, e, todas as direções. $\mathrm{O}$ discurso se encontra com o discurso de outrem e não pode deixar de participar, com ele, de uma interação viva e tensa (Bakhtin, 2014, p. 88).

As palavras de Bakhtin são um ponto de partida fundamental para a reflexão que aqui desenvolvemos sobre os relatórios de estágio. Partimos do pressuposto de que o dialogismo é condição de existência da linguagem, que nossos discursos são produtos da interação social entre sujeitos que pertencem e transitam em diferentes grupos, logo que produzem sentidos distintos sobre a realidade. No encontro entre esses discursos, os sentidos vão se definido com acentos apreciativos definidos sócio-historicamente. Não há palavra neutra, não há sentido 
original e independente do contexto. É na interação e pelo dialogismo que os sentidos vão se constituindo, se estabelecendo, se redefinindo, se propagando, ou seja, nossas palavras estão permeadas da voz alheia; elas se caracterizam por comportar uma dupla dimensão: procederem de alguém e se dirigirem a alguém. As palavras funcionam como uma ponte entre mim e o outro e, ao mesmo tempo, são um território comum a quem está nas extremidades da ponte.

Bakhtin se opõe à concepção estruturalista da língua e coloca em cena a enunciação como unidade de base da língua, uma réplica do diálogo social. A enunciação, nessa perspectiva, é um ato de criação individual único e que não pode ser repetido. Entretanto, em cada enunciação existem pontos iguais aos de outras enunciações, traços idênticos que indicam uma certa estabilidade e favorecem a compreensão dos interlocutores de uma mesma comunidade. Compreender não pode ser entendido como uma atividade passiva, nem como uma uniformidade, isso porque entre os pontos idênticos existem os pontos cegos relativos à localização do sujeito que o impedem de ver tudo. Ele precisa do outro, do lugar em que encontra ajuda para perceber o que estava fora do campo de visão e, tal como uma reação em cadeia, muitos outros vão trazendo luz aos pontos cegos. Essa luz, no entanto, não gera imagens idênticas, ao contrário, completar a visão do outro não é garantir a duplicidade, tal como o reflexo de um espelho. Na relação entre o eu e o outro a luz sofre refração, sofre vários desvios, gera imagens variadas e incertas. A compreensão é marcada por oposições. Por isso, ela é dialética. Nas palavras de Bakhtin/Volóchinov (2006, p. 137), "só a corrente da comunicação verbal fornece à palavra a luz de sua significação".

Os sentidos não estão prontos assim como o sujeito não é senhor de suas intenções. É na relação dialógica com o outro que o sujeito mergulha no fluxo da língua e experiencia o despertar da consciência linguística, a compreensão da palavra em um dado contexto. A palavra "só se torna 'própria' quando o falante a povoa com sua intenção, com seu acento, quando a domina através do discurso, torna-a familiar com a sua orientação semântica e expressiva" (Bakhtin, 2014, p.100). Esse domínio é um processo tenso e complexo, que se solicita do sujeito um mergulho na corrente da comunicação verbal marcado por uma pluralidade de vozes.

A recepção do discurso alheio não está destituída de uma atitude avaliativa. Logo, toda compreensão é uma resposta, uma aproximação 
entre o signo apreendido e outros signos já conhecidos, que se processa no discurso interior, inseparável do sujeito, segundo Bakhtin/ Volóchinov (2006, p. 154), é "no quadro do discurso interior que se efetua a apreensão da enunciação de outrem, sua compreensão e sua apreciação, isto é, a orientação ativa do falante". Desse processo que envolve encontros e desencontros de pontos de vista, de interação, nasce o signo prenhe de sentidos, o discurso carregado de vozes.

Com o objetivo de mostrar a interação na materialidade da língua, Bakhtin faz um estudo das formas sintáticas considerando o contexto, a partir do romance. A obra de Dostoiévski representa a concepção bakhtiniana de dialogismo e pluralidade de vozes na constituição da linguagem, é uma escrita que permite visualizar a palavra alheia no dizer do sujeito, retomada como o discurso no discurso e, ao mesmo tempo, um discurso sobre o discurso. Pela análise da narrativa, Bakhtin (2015) mostra que as fronteiras entre o discurso de outrem e o meu são fluídas, que ainda que sejam utilizados recursos para isolar o que é meu e o que é do outro - tal como as delimitações feitas pelas aspas - as fronteiras continuam permeáveis. Os contornos são estratégias de compreensão.

O romance de Dostoievski é o terreno fértil para demonstrar a interação e as tensões entre os discursos. Cada personagem não tem seu dizer orientado pelo ponto de vista do autor, como aquele que sabe tudo e por isso oprime a diversidade de sentidos e os reduz ao seu próprio ponto de vista. Ao contrário, os personagens têm seu discurso o máximo possível preservado e relacionado com a realidade vivida, não são apenas objetos do discurso do autor, mas sujeitos do discurso, que têm um modo próprio de se expressar e suas palavras carregam um conteúdo específico.

Nessa encenação, o interlocutor também se faz presente. Ele faz parte do processo de interação. É, portanto, um aliado. A organização das vozes, feita pelo autor, em esquemas como discurso direto, indireto e suas variantes, não são apenas recursos gramaticais, ela demonstra tanto a compreensão sobre o conteúdo e a expressão dos personagens quanto a relação com o interlocutor. De acordo com Bakhtin (2015, p.13), o discurso verbal é um evento social, qualquer locução seja ela falada ou escrita "é expressão e produto da interação social de três participantes: o falante (autor), o interlocutor (leitor) e o tópico (o que ou o quem) da fala". 
O paralelo que podemos fazer dessas análises do romance com a discussão do relatório de estágio diz respeito aos modos como o estagiário mobiliza as vozes ao escrever sobre sua prática, como interage com os diferentes discursos que envolvem a aula de língua materna.

A partir do pensamento bakhtiniano sobre o dialogismo, sobre a interação entre o eu na construção de um dizer, interrogamos o relatório de estágio de alunos de Letras, enquanto discurso de um futuro professor graduado que precisa saber manejar com várias vozes e fazê-las aparecer não como objetos do discurso, mas sim como sujeitos. O relatório é a escrita sobre o contato com a escola, com a sala de aula, com professores e alunos. É um enunciado que tem uma forma de organização orientada, um interlocutor específico: o professor que irá atribuir uma nota e um tópico a ser explorado. O relatório, então, é uma resposta ativa sobre a compreensão que o graduando carrega sobre o ensino de língua, uma compreensão que leva em conta um feixe de vozes, dentre as quais, aquelas que representam o discurso acadêmico e aquelas que representam o discurso oficial ${ }^{5}$. O modo de lidar com esses discursos no próprio discurso é o que nos interessa, uma vez que esse manejo está diretamente relacionado com a formação do professor e sua atuação no ensino de língua.

Considerando que essa escrita se define também por elementos externos à língua, apresentaremos a seguir a forma de organização do estágio que acontece de modo geral no Brasil e de modo específico na instituição onde foram coletados os relatórios em estudo.

\section{RELATÓRIO DE ESTÁGIO NO BRASIL: UM CORPUS A SE OBSERVAR}

No Brasil, o Conselho Nacional de Educação e o Conselho Pleno, por meio da Resolução CNE/CP 2, de 01 de julho de 2015 instituem a duração e a carga horária dos cursos de licenciatura, de graduação plena, de formação de professores da Educação Básica em nível superior. Um curso licenciatura precisa destinar 400 horas para o estágio curricular supervisionado, que deve acontecer de modo fracionado ao longo da graduação. Cada instituição deve distribuir e organizar o que

5 Chamamos discurso oficial aquele que chega à escola a partir de documentos como orientações curriculares nacionais sobre o que deve ser abordado em sala de aula e, ainda, aos livros didáticos que seguindo essas orientações apresentam o conteúdo a ser ensinado e ainda o como ensinar. 
será trabalhado, a partir de normas específicas de funcionamento do estágio para cada licenciatura.

Dada a importância das normas para a produção dos relatórios, apresentamos a forma de distribuição da carga horária do estágio, no curso de Letras da Universidade Federal do Rio Grande do Norte, onde foi coletado o material que vamos analisar. A estrutura curricular da Licenciatura em Letras com habilitação em Língua Portuguesa ${ }^{6}$ é formada em sua totalidade por 2800 horas distribuídas em 8 semestres, das quais 400 horas são destinadas para o estágio, que tem seu início na segunda metade do curso. A cada semestre, o aluno cursa 100 horas levando em conta objetivos específicos: estágio 1 , voltado para a observação da escola; estágio 2 caracterizado como participação ativa na escola; estágios 3 e 4 voltados para observação e regência de sala de aula no ensino fundamental e no ensino médio, respectivamente. No manual do estagiário, temos as ementas:

Estágio Supervisionado de Formação de Professores I (100 horas): Orientações gerais para os Estágios Supervisionados de Formação de Professores. Observação da instituição escolar: realidade socioeconômica e gestão. Projeto Político-Pedagógico da Escola e o lugar do componente curricular nessa proposta. Políticas educacionais.

Estágio Supervisionado de Formação de Professores II (100 horas): Participação ativa na vida da escola e da comunidade: acompanhamento das reuniões pedagógicas e dos conselhos escolares; elaboração e desenvolvimento de projetos de integração escola/comunidade, tais como: organização de grupos de estudos com pais, alunos e professores; oferta de minicursos; organização de eventos culturais e outros.

\section{Estágio Supervisionado de Formação de Professores para o} Ensino Fundamental (100 horas): Observação da prática docente,

6 Resolução CNE/CP 2, de 01 de julho de 2015 define que a carga horária mínima de uma licenciatura deve ser de 3200 horas. $\mathrm{O}$ curso de Letras ao qual nos referimos segue a resolução antiga (CNE/CP 2, de 19 de fevereiro de 2002) que instituía como carga horária mínima para curso de formação de professores 2800 horas. 
planejamento e docência supervisionada em sala de aula do Ensino Fundamental, na área de formação do licenciando estagiário.

Estágio Supervisionado de Formação de Professores para o Ensino Médio (100 horas): Observação da prática docente, planejamento e docência supervisionada em sala de aula do Ensino Médio, na área de formação do licenciando estagiário. (Universidade, 2008, p. 11)

Ao término de cada uma dessas etapas, o aluno deve entregar um relatório considerando as orientações do professor e do manual do estagiário. Nessas orientações, constam tanto aspectos formais relativos à estrutura a ser seguida quanto os documentos que devem ser anexados a cada relatório. As informações devem ser distribuídas em partes, levando em conta uma postura reflexiva fundamentada em uma teoria, além disso, o aluno precisa também registrar a importância do estágio para sua formação, as dificuldades encontradas e possíveis sugestões.

Para ter acesso a esses relatórios, entramos em contato com os estagiários e nos deparamos com uma situação que chamou nossa atenção: apenas o primeiro relatório foi produzido individualmente, os três restantes foram escritos em grupos e os componentes mudam a cada novo relatório. Como o uso dos relatórios precisa ser autorizado pelos estagiários e encontrar os membros de cada grupo é demorado, selecionamos um conjunto de quatro relatórios com um ponto em comum: terem pelo menos uma pessoa em comum a todos os grupos.

Temos então um conjunto de quatro relatórios com a seguinte composição: a) estágio I - A1; b) estágio II - A1, A2, A3; c) estágio III - A1, A4, A5; d) estágio IV: A1, A6, A7. Não há registro que explique a forma de composição dos grupos.

Essa escrita coletiva está associada às atividades desenvolvidas em grupos, inclusive à regência. As intenções dos professores em indicar esse tipo de produção aos graduandos, ainda que seja um ponto importante a ser investigado, não se configura um ponto de estudo neste trabalho. Levamos em conta que, sendo feita a várias mãos, temos a escrita como representação de vozes de futuros professores, suas reflexões e as formas pelas quais manejam a voz do outro. 


\section{OS DISCURSOS OUTROS NA ESCRITA DO RELATÓRIO DE ESTÁGIO}

A escrita do relatório de estágio é uma atividade de linguagem e como tal é dialógica, constrói-se a partir do encontro de vozes, da compreensão do aluno a respeito dessas vozes. Escrever um relatório com a observação e participação na realidade escolar fundamentado teoricamente não significa aglomerar vozes, mas construir a voz própria como futuro professor formado em um espaço institucional que oferece um conjunto de saberes acadêmicos relativos à língua e ao ensino, uma escrita em que ele maneje a diversidade de vozes e assim se mostre capaz de responder por si mesmo.

No conjunto de relatórios em estudo, encontramos respostas ao manejo com a voz do outro que se distanciam da ideia de responderem por si mesmos enquanto futuros professores de língua materna capazes de problematizar, de relacionar discursos que se opõem. A escrita traz uma leitura da escola muito mais próxima do discurso do senso comum propagado pelos meios de comunicação que aponta culpados e soluções, ou do discurso oficial que chega pelos parâmetros curriculares nacionais, fazendo prescrições e, com isso, perde a oportunidade de fazer da aula de português um espaço de pesquisa.

Considerando a recorrência de alguns pontos no conjunto dos relatórios, o fato de que o registro da regência só aparece no último relatório e ainda o espaço limitado que temos para explorar os dados neste artigo, recortamos os dados que seguem apenas do último relatório.

Um primeiro ponto que levantamos foi a repetição de determinadas "palavras de efeito". As palavras "crítica" e "reflexão" quer sejam combinadas entre si ou com outras palavras ou sozinhas; quer sejam ainda usadas como substantivos ou derivando outras classes gramaticas, aparecem como o ponto central para a qualidade do ensino. No último relatório considerado pelos estagiários como o mais importante por encerrar as experiências vividas no estágio, vemos o valor atribuído às palavras. Ainda que a escrita seja elaborada coletivamente, ela fica presa aos limites dos sentidos imediatos da palavra, como pode ser visto nos enunciados que seguem. 


\section{Enunciado 1}

O estágio no Ensino Médio nos parece ser o mais importante pelo fato de encerrar um ciclo de relações com a sala de aula, que tem início nas observações dos primeiros estágios. Ao longo desse percurso vamos concebendo um olhar mais atento e ancorado na realidade de cada instituição, levando-nos a tomar uma postura mais crítica e reflexiva a respeito das próprias disciplinas de Estágio Supervisionado, da nossa atuação docente e das questões que cercam o ensino público brasileiro (p. 5).

\section{Enunciado 2}

Retomemos aqui as ideias centrais do discurso freireano, tão repercutido e pouco refletido na prática (p.14).

No enunciado 1, presente na apresentação do relatório, temos as palavras "crítica" e reflexiva" relacionadas à postura do estagiário em relação ao estágio, enquanto componente curricular ligado diretamente à pratica de ensino na escola. No enunciado 2 , retirado das considerações finais, temos o anúncio de voz reconhecida por defender um ensino voltado para uma educação crítica e libertadora. A voz de Paulo Freire, educador brasileiro, é tratada como uma espécie de âncora na qual é possível agarrar-se para justificar a relação entre a teoria e a prática na fundamentação do relatório.

$\mathrm{O}$ efeito que a repetição dessas palavras gera acaba por ir em direção diferente da dúvida tão necessária à pretendida postura crítica e leitura reflexiva. Em dezenove páginas do relatório, há dezenove combinações dessas palavras, mas ainda que coloquem em cena vozes diferentes elas funcionam como se os sentidos fossem equivalentes, falta o remover de camadas semânticas e expressivas, falta a compreensão da palavra enquanto um conceito teórico. Essa falta indica um tratamento do signo linguístico como portador por si mesmo de uma significação independente do contexto.

A significação, no entanto, não pode ser isolada e o signo não pode ser tratado como se fosse uma coisa física (Bakhtin, 2014). É preciso colocar em jogo as camadas semânticas e expressivas da palavra. O efeito dessa falta provocou uma restrição dos sentidos do discurso outro: crítica e reflexão transformam-se em uma coisa física.

A delimitação desses sentidos é reforçada quando é feita a descrição das atividades de ensino planejadas pelos estagiários. É feito um inventário sobre as dificuldades para a realização do que intencionavam 
realizar, os problemas estavam no que é externo ao planejamento feito, não há a assunção da responsabilidade sobre o próprio fazer.

\section{Enunciado 3}

Ressaltamos que nossa conduta, no caso do estágio, passa por uma série de questões que muitas vezes são maiores do que nossas próprias intenções.

[...], tivemos alguns problemas com o número de aulas, desde a greve até o cancelamento pontual de outros dias letivos $[\ldots]$ (p. 5).

Não encontramos no relatório o plano pensado e não concretizado. Mas o enunciado acima representa as várias passagens relativas à concepção de crítica e de reflexão ancoradas na queixa. As forças externas e identificadas pelos alunos como: a greve de professores e o cancelamento de aula não são problematizadas. A greve é vista apenas como algo que atrapalha o que foi planejado pelos estagiários dentro de um intervalo de tempo. O que a greve significa em termos político-pedagógicos para o professor foi silenciado. $\mathrm{O}$ cancelamento de aulas também não é problematizado, mas tratado com algo que compromete o trabalho.

Não queremos com isso negar as relações de força que existem dentro do sistema de ensino ou atribuir ao professor a responsabilidade pelos problemas que envolvem esse sistema. O que apontamos aqui é a queixa que se propaga como justificativa para pouca qualidade das práticas de ensino e que se reproduz como se fosse natural.

Esse movimento mostra a compreensão dos alunos, a palavra adquirida do outro que se apresenta não mais na qualidade de informações, "ela procura definir as próprias bases de nossa atitude ideológica em relação ao mundo e de nosso comportamento, ela surge como palavra autoritária e como palavra interiormente persuasiva" (Bakhtin, 2014, p. 142). Para resistir a essa persuasão, é preciso olhar para o outro, buscar entender o que ele vê, ampliar o campo de visão do eu e, ao voltar para o próprio lugar, enxergar o que estava no ponto cego.

A dificuldade de colocar-se na posição do outro, ainda que esteja na condição de aprendiz de um ofício, faz com que os estagiários coloquem-se como juízes capazes de julgar e emitir um veredito sobre as atividades de ensino desenvolvidas pelos professores da escola. 


\section{Enunciado do relatório 4}

A organização educacional acaba contribuindo para uma prática não tão eficaz, não existe na escola uma coordenadora que auxilie os alunos e os direcionem para a sala de aula. Não identificamos também nenhuma das diretrizes do chamado Ensino Médio Inovador, em que se deveria buscar práticas diferenciadas que atendessem aos vários interesses desses alunos que partirão para o campo profissional (p. 7).

Aqui há um jogo de imagens: de um lado o estagiário que sente seu desempenho como professor prejudicado e que por isso pode e deve ser visto como vítima de um sistema, de uma escola que não oferece condições suficientes para um ensino de qualidade; de outro lado está o estagiário que assume a posição de avaliador e assim desconsidera o que ele mesmo apresentou como dificuldades para realizar o trabalho e assim faze um juízo de valor negativo sobre as ações pedagógicas dos professores.

O papel da coordenação pedagógica reduz-se a fazer com que os alunos cheguem às salas de aula, e como isso não ocorreu, a função da coordenadora não foi cumprida, é inexistente. Não há, no relatório, referências à relação entre professores e coordenação, e apenas uma breve apresentação de uma aula do professor responsável pela turma que justifique dizer que não existem ações referentes a um ensino médio inovador. Ou seja, há um modelo de ensino, uma referência sobre o que ensinar em desencontro com o que o estagiário vê sem sair de seu lugar, logo uma visão muito limitada. Desse modo, o pensar, que deveria ser relacional, cede lugar ao julgamento e veredito negativo sobre o trabalho docente.

O relatório mostra o peso da experiência primeira, carregada do que Bachelard (1996) chama de surdas paixões, e que não constitui base segura para a formação do espírito científico. Essas impressões iniciais são um obstáculo quando colocados antes e acima da dúvida sobre o que está posto, pois não permitem o surgimento da crítica como elemento inerente à produção do conhecimento.

Ainda sobre a relação entre a crítica e as impressões primeiras, levantamos na escrita da breve descrição feita sobre a aula do professor responsável pela turma, um ponto que parecia ser a emergência de inquietação necessária à formação do professor como um pesquisador de sua própria prática e dos fenômenos da linguagem. A escrita mostrou as impressões dos estagiários sobre o trabalho com o livro didático, 
apontado como principal instrumento para o estudo da língua, sobre o conteúdo explorado e as práticas de ensino que acontecem na sala de aula, sob a regência do professor da escola.

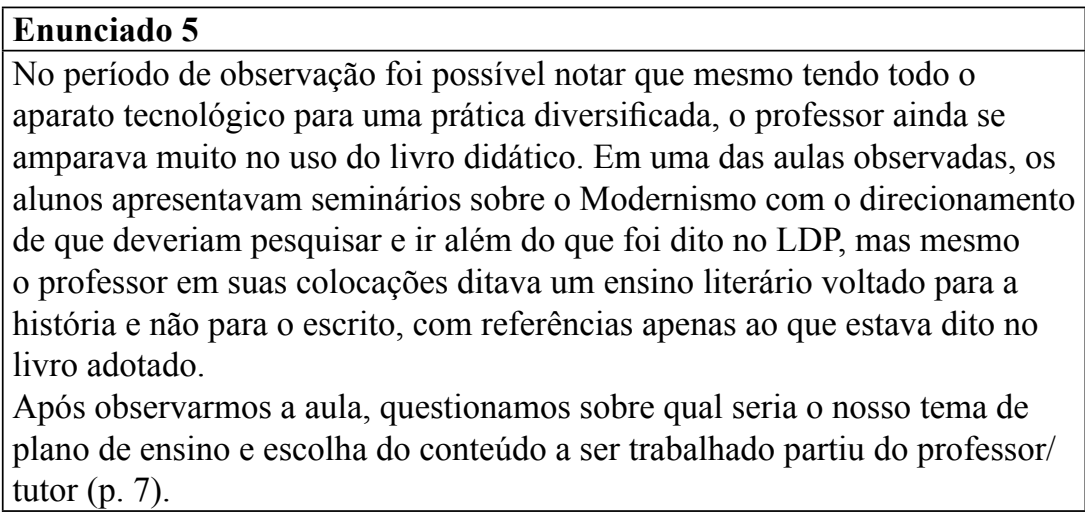

Os indícios de uma observação produtora de uma dúvida a ser investigada, a respeito da aula de português, desfizeram-se no parágrafo seguinte. O professor é apresentado como aquele que tem práticas tradicionais, que não faz uso da tecnologia digital oferecida pela escola, que dita o conteúdo do livro didático como única fonte do saber e ainda como professor incoerente, uma vez que solicita dos alunos pesquisa, mas não a realiza. Sobre os alunos da sala de aula observada, é dito apenas que apresentaram trabalhos, ou seja, são desconsiderados, como se pertencessem ao cenário cujos atores são o professor regente e os estagiários.

Essas impressões não se tornaram crítica, no sentido da formação do espírito científico, elas são a confirmação de que impressões primeiras que conduzem o relatório promovem o julgamento negativo do trabalho do professor, silenciamento dos alunos e, ao mesmo tempo, esse relatório mostra passividade dos estagiários no que se refere a elaborar um plano de aula, a assumir a regência da sala, como pode ser visto no enunciado 5 .

Ao término da observação do trabalho desenvolvido pelo professor, os estagiários não sugerem um conteúdo a ser trabalhado em sala de aula, mas perguntam ao professor o que ensinar. Saem da posição de juízes assumem a posição de alunos que buscam respostas prontas. A pergunta funciona como um disfarce para evitar o enfrentamento com a situação, com o não-saber-como-fazer para ensinar. A resposta 
do professor é uma proteção e um encaminhamento a ser seguido pelo aprendiz, o qual precisa ser "autorizado" a tomar decisões sobre a sala de aula.

A escrita do relatório mostra o jogo da mudança de cadeiras de acordo com o tempo da música, um jogo perigoso porque não há preocupação em colocar-se no lugar do outro e ampliar o campo de visão, mas de olhar apenas para um lado, com a preocupação de não ficar sem cadeira.

As formas de lidar com a voz do outro a fim de justificar a defesa de uma posição referem-se também aos autores convocados como representantes do discurso acadêmico e do discurso oficial.

\begin{tabular}{|c|c|}
\hline Enunc & ciado 6 \\
\hline $\begin{array}{l}\text { Ampar } \\
\text { dentro } \\
\text { pudess } \\
\text { a respe }\end{array}$ & $\begin{array}{l}\text { rados por Freire (1996) e pelos próprios PCN'S, procuramos } \\
\text { da nossa prática em sala, trazer, dentro do possível, elementos que } \\
\text { sem de algum modo suscitar esse olhar menos limitado e mais crítico } \\
\text { eito do mundo, por intermédio da língua materna (p. 5). }\end{array}$ \\
\hline Enunc & ciado 7 \\
\hline $\begin{array}{l}\text { Mantiv } \\
\text { conhec } \\
\text { o profe }\end{array}$ & $\begin{array}{l}\text { vemos o foco em um ensino voltado para o diálogo e a construção do } \\
\text { cimento por meio da interação, tanto entre eles, os alunos, quanto com } \\
\text { essor. Para Bakhtin/Volóchinov: }\end{array}$ \\
\hline & $\begin{array}{l}\text { Na realidade, toda palavra comporta duas faces. Ela é determinada } \\
\text { tanto pelo fato de que procede de alguém, como pelo fato de que se } \\
\text { dirige para alguém. [...] (Bakhtin/Volóchinov, } 2004 \text { [1929], p. 113). }\end{array}$ \\
\hline . 8) & \\
\hline
\end{tabular}

Nas referências bibliográficas de todos os quatro relatórios, encontramos os mesmos autores, como se há quatro semestres houvesse a leitura de Paulo Freire, Mikhail Bakhtin, Luiz Antonio Marcuschi, João Wanderley Geraldi. Essas vozes aparecem como uma espécie de garantia sobre a validade do sentido das palavras "crítica" e "reflexão" adotado pelos estagiários. Os dois primeiros autores são colocados como os principais, com se bastasse citar essas vozes para garantir uma escrita cientificamente legitimada, mas essa mera citação dos autores não garante a legitimidade porque esbarra em um grande obstáculo: o uso conceitos científicos como palavras de sentido comum, dicionarizado ou ainda a aproximação de sentidos como se fossem sinônimos. 
Autores como Paulo Freire, que defende um ensino contextualizado, voltado para a aprendizagem da leitura e escrita como forma de liberdade e autonomia, e ainda o discurso oficial dos Parâmetros Curriculares Nacionais (PCN), que diz o quê e como deve acontecer o ensino de língua nas escolas, são utilizados como discursos convergentes e sinônimos.

Outra situação observada diz respeito citar a voz do outro como se fossem ilha. A citação direta, usada após a avalição que os estagiários fazem do próprio trabalho, é uma resposta estratégica às exigências de produção do relatório. No enunciado 7 , temos uma passagem em que a voz de Bakhtin usada aos moldes das estratégias de recorte e cola, forma uma colcha de retalhos sem harmonia. A interação e a dupla face da palavra tiveram seu sentido reduzido ao diálogo face a face com o professor, se levarmos em conta o relatório como um todo. A voz citada como argumento de autoridade, aproxima-se do que Bachelard (1996) chamou de obstáculo substancialista, uma referência verbal com referência a um substantivo com ricos poderes.

No encontro de vozes que acontece no relatório, o estagiário coloca: o professor regente como a voz ditadora, distanciada da pesquisa e dos avanços tecnológicos; os autores citados como a voz do saber acadêmico; os PCN como a voz a oficial; a si mesmo como a voz de um aprendiz, atualizado que foi capaz de desenvolver "um ensino voltado para o diálogo e a construção do conhecimento" (Enunciado 7). Ou seja, coloca-se em posição superior à do professor, não se dá conta de como repete o discurso negativo sobre a escola e o professor, que nada tem de crítico; de como tem uma compreensão lacunada sobre os sentidos da palavra em diferentes discursos.

Considerando o que diz Bakhtin (2014), de que todo discurso é orientado para ser resposta, o relatório é uma resposta que não pode ser vista à luz de um documento burocrático. Seu sentido é plural, principalmente se for tratado como uma resposta sobre a formação de professores e, nesse caso, é alto o índice de refração.

\section{CONSIDERAÇÕES FINAIS}

Nossa proposta, com este artigo, foi a de socializar discussões sobre a escrita do relatório de estágio que estamos desenvolvendo coletivamente. Nossa preocupação voltou-se para o modo como os estagiários lidam com o discurso científico na fundamentação de suas reflexões sobre o ensino, que vozes convocam e que valor atribui a elas. 
Vimos, no conjunto dos dados selecionados que, entre vozes, o relatório foi se definindo e mostrando os sentidos que os alunos carregam sobre a escola, a docência, a pesquisa, mostrando como uma escrita, que deveria trazer uma experiência de aprendizagem sobre ensino, vai se estabelecendo como uma espécie de alerta sobre a qualidade da leitura realizada pelos estagiários, pelo nível de questionamento que elaboram, pelo tipo de observação que realizam. Um alerta para a concepção de ensino e pesquisa na graduação.

Observar a sala de aula e a escola não significa assumir a posição de investigador à procura de provas de acusação contra o professor a partir de uma imagem que supõe-se ser um ensino ideal, crítico e interativo. Perseguir essa imagem, como se fosse um modelo a ser seguido é cair em uma armadilha. Resistir à tentação de encontrar erros diante e tantos diagnósticos negativos sobre a escola e o ensino é um desafio, que não se vence sozinho, porque demanda aprendizagem, logo, a ação de um professor que ensine.

Os discursos de Mikhail Bakhtin, Paulo Freire ou dos Parâmetros Curriculares Nacionais precisam ser aprendidos como vozes diferentes, que se afinam em alguns pontos e se afastam em outros. O discurso do professor responde a outros discursos. Entender essas respostas é fundamental. É esse entendimento e são essas distinções que podem promover efetivamente a crítica e a reflexão necessárias à formação de um professor com espírito científico.

\section{Referências}

Bachelard, G. (1996). A formação do espirito científico: contribuição para uma psicanálise do conhecimento. Rio de Janeiro: Contraponto.

Bakhtin, M. (2014). A pessoa que fala no romance. In: BAKHTIN, Mikhail. Questões de literatura e de estética: a teoria do romance. 7. ed. São Paulo: Hucitec Editora. . (2015). Discurso em Dostoievsky. In: BAKHTIN, Mikhail. Problemas da poética de Dostoiévski. 5. ed. Rio de Janeiro: Forense Universitária.

Bakhtin, M; Volóchinov, V. N. (2015). Discurso na vida e discurso na arte: sobre poética sociológica. Disponível em: www.uesb.br/ppgcel/Discurso-Na-Vida-Discurso-Na-Arte.pdf 
. (2006). Marxismo e filosofia da linguagem. 12. ed. São Paulo: HUCITEC.

Brasil. Ministério da Educação. (2015). Conselho Nacional de Educação. Resolução $N^{\circ}$ 2, de $1^{\circ}$ julho de 2015. Brasília, DF. Disponível em: http://pronacampo.mec.gov.br/images/pdf/res_cne_ cp_02_03072015.pdf

Geraldi, J. W. (2010). A aula como acontecimento. São Carlos: Pedro \& João Editores.

Universidade Federal do Rio Grande do Norte. (2008). Manual do estagiário. Natal: UFRN. 